\title{
Phenotypic correlation among morphometric traits in new zealand white rabbits reared under tropical condition
}

${ }^{*+}$ Abe, O. S., Amusan, S. A. ${ }^{\$}$ and Ozoje, M. O.

"Department of Animal Breeding and Genetics, Federal University of Agriculture, Abeokuta, Nigeria

${ }^{+}$Department of Animal Health and Production Technology, Aquatech College of Agriculture and Technology, Ibadan, Nigeria

${ }^{\S}$ Department of Animal Production, Federal College of Animal Health and

Production, Moor Plantation, Ibadan, Nigeria

Correspondence author: abeolugbenga@gmail.com; 08138083808

\section{Abstract}

A total of 48 New Zealand White (NZW) rabbit was used for the phenotypic estimation study. After two weeks of birth, the kittens were introduced to commercial grower mash (CGM) and were fed solely on the commercial grower mash diets with the following characteristics; $17.5 \%$ crude protein, $16 \%$ crude fibre and $2500 \mathrm{kcal} / \mathrm{kg}$ diet digestible energy ad libitum. Morphometric traits such as Fore Limb (FL), Hind Limb (HL), Body Length (BL), Thigh Girth (TG), Abdominal Circumference (AC) and Leg Length (LL) in NZW rabbit were measured on the rabbit with the aid of measuring tape in centimetre (cm) at 4, 8 and 12 weeks of age. The first measurement was taken on the day of weaning (4 weeks). The data obtained was analysed using the simple linear correlation procedure of SAS analytical package to obtain the correlation between the various morphometric traits studied. The study lasted for 12 weeks. From the study the phenotypic correlations obtained were all positive and ranged between moderate (0.47, the lowest value) and high (0.89, the highest value) correlated value for all ages considered for the NZW rabbit. The result further showed that BL was highly correlated $(<70)$ with other morphometric trait at 4 and 12 weeks of age. Moderate correlation was recorded more at the 8 weeks of age of the rabbit when compared to 4 and 12 weeks of age. The TG and HL recorded the highest correlation value among the other morphometric traits at 4, 8 and 12 weeks of age. This shows that as the animal grows, there is a positive relationship between the various morphometric traits and further implies growth is more inclined in other part of the body than FL and LL immediately after weaning while it evened out after 4 weeks of age.

Keywords: New Zealand rabbit, morphometric traits, correlations, hind limb, fore limb

\section{Introduction}

Rabbit production is one of the ways that can be exploited if we are to combat the shortage of animal protein in developing countries, especially Nigeria. Rabbit production is gradually becoming an important source of income and employment generation in Nigeria (Olawumi, 2014). Rabbit has so many characteristics that can be harnessed in building the consumption capacity of Nigerian people with respect to daily protein requirement. Rabbits can be considered as one of the several species quite suitable for meat production (Akinsola et al., 2014). They are characterized by quality protein $(20-21 \%)$ having high biological value amino acids, meat low in calories and fat, while the animal is highly prolific with short gestation length, initial capital outlay is minimal, great genetic flexibility, lipids are highly unsaturated $(60 \%$ of the total fatty acids), valuable animal model for 


\section{Phenotypic correlation of morphometric traits in rabbit}

biomedical research, low sodium and cholesterol level and a delicacy for health food products (Dalle, 2002). Breed characterization of livestock is the first approach to a sustainable use of its animal genetic resource (Lanari et al., 2003). The first knowledge of the characterization of local genetic resources falls on the knowledge of the variation of morphological traits (Delgado et al 2001). Morphometric measurements have been found useful in contrasting size and shape of animals (Ajayi et al., 2008). Growth, which is the totality of the bodily development that can be seen phenotypically is the main economic trait needed for improved profitability for farmers and adequate meat for the consumers. Genetic improvement of rabbit is a vital scope on the way to increasing their contribution to the much needed animal protein in developing countries (Okoro et al., 2010). However, the importance and efficacy of rabbit production in Nigeria has not been fully harnessed with respect to the profitability and their impact in meeting the much needed animal protein. In other to reduce the production cost and increase the profitability of rabbit production, genetic improvement of the adapted breed has to be undertaken. One of the pre-requisites for genetic improvement is the knowledge of genetic parameters for important economic traits (Akanno and Ibe, 2006). Towards value addition in rabbit production, rabbit producers are more interested in the various part of the animal body in relation to others to optimize returns on production, as it has direct impact on their feed efficiency and performance. Thus, breeders need to establish the relationship that exists between these morphometric traits and to organize the breeding programmes so as to achieve an optimum combination of bodyweight and good conformation for maximum economic returns (Khalil et al.,
1987). This makes the work of the breeders easier and faster as effects can then be concentrated on traits that are easier to measure. Breeds such as New Zealand white, Dutch and Chinchilla remain the most commonly identified ones which have peculiar characteristics in terms of body weight that distinguish them from one another (Ozimba and Lukefahr, 1991; Okoro et al., 2010). In addition, McNitt and Lukefahr (1993) found that New Zealand White had significantly higher market weight and lower age than California, Palomino and White Satin breeds. Therefore, this study was aimed at measuring the phenotypic correlation coefficient obtainable between morphometric traits in New Zealand White (NZW) rabbits reared in Southwest Nigeria at ages 4,8 and 12 weeks.

\section{Materials and methods \\ Study site}

The study was carried out at the Rabbitry Unit of the Directorate of University Farms, Federal University of Agriculture, Abeokuta (FUNAAB), Nigeria. The farm lies on the Latitude $7^{\circ} 10^{\prime}$ North in Odeda Local Government Area, Ogun State within the rain forest belt of South Western Nigeria. The Longitude is $3^{0} 2^{\prime}$ East with altitude 76 masl. The climate is humid with a mean annual rainfall of $1,037 \mathrm{~mm}$, mean temperature of $34.7^{\circ} \mathrm{C}$ during the period and mean relative humidity of $82 \%$. The vegetation interplays between tropical rainforest and derived savannah.

\section{Experimental animals and management}

A total of 48 New Zealand White rabbit kittens were used for the phenotypic parameter estimation study. The kittens after birth were allowed to stay with the doe till 28 days before being weaned. After weaning at day 28 , the rabbits were housed in wooden cages with wire mesh floor $(40 \times$ $50 \times 60 \mathrm{~cm})$ and were provided with 


\section{Abe, Amusan and Ozoje}

concrete feeders and watering system. Four rabbits were kept per cage to avoid overcrowding and easy access to feed and water. After two weeks of birth, the kittens were introduced to the commercial grower mash and were fed the same till the end of the study. The commercial grower mash diets contain the following; $17.5 \%$ crude protein, $16 \%$ crude fibre and $2500 \mathrm{kcal} / \mathrm{kg}$ diet digestible energy. The feed and water were provided to the animal ad libitum. Routine management of drug administration as and when due and other sanitation procedures was observed throughout the period of the study. Though no major disease or mortality was recorded during the study period.

\section{Data collection}

The linear body measurement of individual rabbits was taken at 4,8 and 12 weeks with the aid of a measuring tape in centimetre $(\mathrm{cm})$ at the same period by same individual to avoid between individual measurement differences. Six linear body traits were measured on each animal using the anatomical procedure described by Gueye et al. (1998), Kathiravan (2008) and Teguia et al. (2008). The quantitative characters measured were Fore Limb (FL) which was measured from the shoulder blade to the point of phalanges, Hind Limb (HL) which was measured from the point of disc plate to the ankle, Body Length (BL) was measured as the diagonal distance from the point of the shoulder to the pin bone, Thigh Girth (TG), Abdominal Circumference (AC) was measured as circumference of the thoracic cavity just behind the fore limbs and Tail length (TL) measured from the base of the tail to the tip (coccygeal vertebrae).

\section{Statistical analysis}

The phenotypic correlations of the morphometric traits at different ages were estimated using the simple linear correlation procedure of SAS (2000) analytical package to examine the linear relationship and association between the different linear traits at different ages. The correlation coefficient between the different weights are written as:

$$
r=\frac{\sum X Y}{\sqrt{\sum X \sum Y}} \quad i=1, \ldots, N
$$

Where $\quad r=$ pearson product moment correlation coefficient

$$
\mathrm{X}_{i}=\text { the first random }
$$

variable of the ith linear body measurement

$$
\mathrm{Y}_{i}=\text { the second random }
$$

variable of the ith linear body measurement The Pearson correlation is defined between -1 and $+1(-1 \leq r \leq 1)$ where -1 indicates a perfect decreasing (negative) linear relationship, +1 indicates a perfect positive (increasing) linear relationship and some values between -1 and +1 in all other cases indicate the degree of linear relationship between the $\mathrm{X}$ and $\mathrm{Y}$ parameters.

\section{Results and discussion}

The results of the phenotypic correlations are as presented in Tables 1, 2 and 3. As observed from the tables for all ages considered, the phenotypic correlation coefficient values, among the morphometric traits in all the ages, ranged from moderate to high correlation, and were all positive (Tables 1-3), which means that as any one morphometric trait is increasing, a corresponding increase is expressed in the other (Olawumi, 2014). According to ElLabban (1999), positive relationships between these traits were as a result of pleiotropic effect of genes and linkage effects which operate on these traits. This shows that morphometric growth in NZW rabbit is asymmetrical with other body parts. It is also indicative that as this breed of rabbit grows, all the other parts are growing concurrently. The high phenotypic correlation between the morphometric traits in this study agreed with the report of 


\section{Phenotypic correlation of morphometric traits in rabbit}

Janssens and Vandepitte (2004) and Oke et al. (2004) who found positive, and high significant $(p<0.01)$ correlations between their morphometric traits of interest. It further showed that any attempt to perform phenotypic selection for one trait will consequently result in improvement of the other (Olawumi, 2014). The highest phenotypic correlation coefficient value of 0.82 was obtained between TG and HL while the lowest of 0.54 was obtained between LL and TG at 4 weeks of age. This indicated that TG and HL are highly correlated which may be due to that fact that they are on similar proximity of the animal.
However, at 8 weeks of age (Table 2), TG and HL were highly correlated (0.89) among other morphometric traits. The lowest phenotypic correlated value of 0.47 was obtained between TG and FL (Table 2). This showed that TG is an important trait to consider in selection process as it has interference in the outcome of either high or low correlations value. In Table 3, HL and FL were lowly correlated phenotypically followed by LL and AC. However, HL was highly correlated with TG (0.82) and LL (0.82). TG at 8 weeks of ages showed high correlation with one trait or the other, especially with HL and LL.

Table 1: Phenotypic correlation of morphometric traits in NZW rabbit at 4 weeks of age

\begin{tabular}{lllllll}
\hline Parameters & FL & HL & BL & TG & AC & LL \\
\hline FL & & & & & & \\
HL & 0.55 & & & & & \\
BL & 0.78 & 0.62 & & & & \\
TG & 0.68 & 0.82 & 0.75 & 0.63 & & \\
AC & 0.77 & 0.68 & 0.70 & 0.75 & 0.63 & \\
LL & 0.65 & 0.75 & 0.70 & 0.54 &
\end{tabular}

$\mathrm{FL}=$ Fore limb, $\mathrm{HL}=$ Hind limb, $\mathrm{BL}=$ Body length and $\mathrm{TG}=$ Thigh girth, $\mathrm{AC}=$ Abdominal circumference, $\mathrm{LL}=$ Leg length

Table 2: Phenotypic correlation of morphometric traits in NZW rabbit at 8 weeks of age

\begin{tabular}{lcccccc}
\hline Parameters & FL & HL & BL & TG & AC & LL \\
\hline FL & & & & & \\
HL & 0.68 & & & & \\
BL & 0.53 & 0.76 & & & \\
TG & 0.47 & 0.89 & 0.50 & & \\
AC & 0.72 & 0.77 & 0.55 & 0.75 & 0.80 \\
LL & 0.82 & 0.66 & 0.69 & 0.65 & \\
\hline FL = Fore limb, HL = Hind limb, BL = Body length and TG = Thigh girth, AC = Abdominal \\
circumference, LL = Leg length
\end{tabular}

Table 3: Phenotypic correlation of morphometric traits in NZW rabbit at 12 weeks of age

\begin{tabular}{lllllll}
\hline Parameters & FL & HL & BL & TG & AC & LL \\
\hline FL & & & & & & \\
HL & 0.55 & & & & & \\
BL & 0.78 & 0.62 & & & & \\
TG & 0.68 & 0.82 & 0.75 & & \\
AC & 0.77 & 0.68 & 0.70 & 0.63 & & \\
LL & 0.65 & 0.82 & 0.68 & 0.61 & 0.59 & \\
\hline
\end{tabular}

$\mathrm{FL}=$ Fore limb, $\mathrm{HL}=$ Hind limb, $\mathrm{BL}=$ Body length and $\mathrm{TG}=$ Thigh girth, $\mathrm{AC}=$ Abdominal circumference, $\mathrm{LL}=\mathrm{Leg}$ length 
This study revealed that positive, and moderate to high phenotypic correlation values exists between morphometric traits in NZW breed of rabbits. This is an indication that growth in this breed of rabbit is evenly and well distributed around the body as reported by Olawumi (2014). Furthermore, the study revealed that TG is highly correlated with other traits of interest and fortunately it's among the parts of the animal that is well sought after by consumers. This showed that as TG grow bigger other parts like LL and HL will show a corresponding weight increase. This is however, a good indicator for rabbit breeders and producers who aimed at morphometric traits for optimizing their production process by targeting TG, LL and HL production.

\section{References}

Ajayi, F. O., Ejiofor, O. and Ironke, M. O. 2008. Application of principal component and discriminant analyses to morphostructural indices of indigenous and exotic chickens raised under intensive management system. Tropical Animal Health and Production, 44(6): 1247-1254

Akanno, E. C. and Ibe, S. N. 2006. Prediction of body weight of the domestic rabbits at different stages of growth using linear body measurements. Nigerian Journal of Animal Production, 33(1):3-8.

Akinsola, O. M., Nwagu, B. I., Or u n m u i, M ., I y e g h e Erakpotobor, G. T., Eze, E. D., Abanikannda, O. T. F., Onadepo, O., Okuda, E. U. and Louis, U. 2014. Prediction of bodyweight from body measurements in rabbits using principal component analysis, Annals of Biological Sciences, 2 (1):1-6

Dalle Zotte, A. 2002. Main factors influencing the rabbit carcass and meat quality. Proceedings of the 7th World Rabbit Congress, Valencia, Spain, 1-32.

Delgado, J. V., Barba, C., Camacho, M. E., Sereno, F. T. P. S., Martinez, A. and Vega-Pla, J. L. 2001. Phenotypic variation in growth and biometric traits in rabbit reared in the humid tropics. AGRI, 29, 7-18.

El-Labban, A. F. M. 1999. Comparative studies on phenotypic performance of body measurement and carcass characteristics in males of some local strains of chickens. Egypt Poultry Science, 19:419-434

Gueye, E. F., Ndiaye, A. and Branckaert, R. D. S. 1998. Prediction of body weight on the basis of body measurements in mature indigenous chickens in Senegal. Livestock Research for Rural Development, 10: 22 http://www. Cipav.org.co/Irrd 10/3/sene103. htm.

Ibe, S. N. 2006. Prediction of body weight of the domestic rabbits at different stages of growth using linear body measurements. Nigerian Journal of Animal Production, 33(1): 3-8.

Janssens, S. and W. Vandepitte, 2004. Genetic parameters for body measurements and linear type trait in Belgian Bleu du Maine, Suffolk and texel sheep. Small Ruminant Research, 54: 13-24.

Kathiravan, P., Sadana, D. K., Mishra, B. P., Kataria, R. S., Kaur, P., Kumar, A. and Jayaprakash, N. S. 2008. Survey and Characterization of South Kanara buffaloes in India. Animal Genetic Resource Inf. 43: 6777.

Khalil, M. H., Owen, J. B. and Afifi, E. A. 1987. A genetic analysis of litter traits of bauscat and Giza white rabbits. Animal Production 45(1): 
123-124.

Lanari, M. R., Taddeo, H., Domingo, E., Centeno, M. P. and Gallo, L. 2003. Phenotypic differentiation of exterior traits in local Criollo Goat population in Patagonia (Argentina). Arch Tierz Dummerstorf, 46: 347-356.

McNitt, J. I. and Lukefahr, S. D. 1993. Breed and environmental effects on post weaning growth of rabbits. Journal of Animal Science, 71: 19962005

Oke, U. K., Ibe, S. N. and Ogbnnaya, E. O. 2004. Effect of genotype on growth traits of rabbits. Int. J. Agric. RuralDev., 5: 61-68.

Okoro, V. M. O., Ezeokeke, C. T. and Chukwudum, U. E. O. 2010. Phenotypic correlation of body weight and linear body measurement in Chinchilla rabbits (Oryctolagus cuniculus). Journal of Agricultural Biotechnology and Sustainable Development, 2: 27-29.
Olawumi S. 2014. Comparative study on rabbit breeds for post weaning growth traits in the humid tropics of Nigeria. Global Journal of Animal Scientific Research, 2(1)

Ozimba, C. E. and Lukefahr, S. D. 1991. Comparison of rabbit breed types for post weaning litter growth, feed efficiency and survival performance traits. Journal of Animal Science, 69: 3494-3500

SAS Institute Inc. 2000. The SAS Users Guide: Statistics released version 8.0. Statistical Analysis System Institute. Inc., Cary, NC.

Teguia, A., Ngandjou, H. M., Defang, S. and Tchoumboue, T. 2008. Study of the live body weight and body characteristics of the African Muscovy Duck (Caraina moschata). Tropical Animal Health Production, 40:5-10.

Received: $16^{\text {th }}$ July, 2019

Accepted: $17^{\text {th }}$ December, 2019 